\title{
Effect of the bainitic and martensitic microstructures on the hardening and embrittlement under neutron irradiation of a reactor pressure vessel steel
}

\author{
B. Marini ${ }^{1 *}$, X. Averty ${ }^{2}$, P. Wident ${ }^{1}$, P. Forget ${ }^{1}$, F. Barcelo ${ }^{1}$ \\ ${ }^{1}$ Commissariat à l'Energie Atomique et aux Energies Alternatives, DEN/DANS/DMN/SRMA, F-91191 Gif-sur Yvette, France \\ ${ }^{2}$ Commissariat à l'Energie Atomique et aux Energies Alternatives, DEN/DANS/DMN/SEMI (now DEN/DANS/DM2S/SEMT), F- \\ 91191 Gif-sur Yvette, France \\ * Corresponding author, Tel.: 33(0)1 6908 8599, e-mail : bernard.marini@cea.fr
}

\begin{abstract}
The hardening and the embrittlement under neutron irradiation of a RPV steel considering three different coarse grained microstructures (bainite, bainite-martensite and martensite) have been investigated. Bainite and martensite have a comparable irradiation induced temperature transition shifts but hardening is smaller for martensite than for bainite. Bainite appears to be less sensitive to non-hardening embrittlement (NHE) than martensite. The onset of brittle intergranular fracture after irradiation for the martensitic microstructure is likely the origin of this difference of sensitivity to NHE. However, the bainitic-martensitic microstructure has the largest irradiation induced shift and is the most sensitive to NHE amongst all the tested microstructures. These results show that the microstructure is an important parameter to control the irradiation induced non hardening embrittlement and the enhancement of the brittle intergranular fracture in reactor pressure vessel steels.
\end{abstract}

Keywords: RPV steel, Irradiation induced embrittlement, microstructure, bainite, martensite

\section{Introduction}

The reactor pressure vessel (RPV) of nuclear power plant is a heavy component built by welding thick parts like rings, nozzles and domes which is be submitted to neutron irradiation. During the fabrication process, low alloy RPV steels are quenched to obtain a bainitic microstructure. Because of the thickness of the wall of the vessel, the cooling rate during the quench varies from few tens of degrees per minutes in the centre to few degrees per second at the vicinity of the surface of the shell [1]. In addition, macro and micro segregation inherited of the solidification of the ingot modify locally the chemical composition of the steel [2]. Welding of the different parts of the vessel and the cladding deposit in the inner face introduce different heat affected zones (HAZ) with coarse and refined grains. Consequently, the microstructure and the initial mechanical properties are not uniform through the wall thickness and along the axis of the vessel. As an example, the transition temperature can vary of several tens of degrees through the thickness [3, 4].

It has been identified since many years that simulated coarse grained heat affected zones present a larger susceptibility to thermal ageing than other microstructuctures. However, this tendency to embrittlement appears to be smaller for real HAZ [5-7].

In a previous study, the response of different coarse grained microstructures of a A533 type steel to step cooling heat treatment have shown a larger susceptibility of martensite to temper embrittlement and the enhancement of intergranular fracture for the microstructures containing martensite. Auger analyses have indicated the segregation of $\mathrm{P}$ on the prior austenite grain boundaries of the martensitic microstructure [8]. It was also observed for a DIN 22NiMoCr37 RPV steel thermally aged à $520^{\circ} \mathrm{C}$, that coarse grained martensite presents mixed transgranular and intergranular fracture for notch specimens as the fracture for the bainite remains, after ageing, transgranular cleavage [9]. Recently, the sensitivity of martensite bearing microstructures to thermal ageing of A508 type steels without prior coarsening of the austenite grain has been demonstrated [7], [10].

Neutron irradiation, in general, increases only slightly the $\mathrm{P}$ segregation at grain boundaries and nonhardening embrittlement of RPV base metals is low [11-13]. However, some cases of irradiation enhancement of brittle intergranular fracture (BIF) are reported in the literature for the formally called "western" RPV base metals (A302, A508 and A533): 
- Increase in BIF and of the phosphorus coverage of the grain boundaries is reported for a A533-B with a content of $0.017 \% w t$ of phosphorus and heat treated to simulate heat affected zone with coarse grains (> $220 \mu \mathrm{m})[11]$.

- Onset of Brittle Intergranular Fracture (BIF) (10\% of the total surface) was observed after irradiation on a A533 B base metal with a content of $0.017 \%$ wt of phosphorus [14]

- Onset of BIF after irradiation on a low phosphorus A302B type steel heat treated to simulate a heat affected zone [15].

- Increase in BIF surface and of the phosphorus coverage of the grain boundaries is reported for a P doped A533-B (570 ppm) [16]

For these cases, it appears that the factors triggering the irradiation enhanced BIF is a high level of $P$ content and/or a coarse grained microstructure produced by austenitization at high temperature.

In this study, we investigate the microstructural conditions of the non-hardening embrittlement and the enhancement of BIF observed under irradiation at RPV service temperature. In this objective, three different microstructures (bainite, bainite-martensite and martensite) with coarse grains have been generated for the same RPV steel by changing the cooling rate during the quench. Their hardening and embrittlement under neutron irradiation are investigated.

\section{Material}

The material used in this study is similar to a 16MND5 type steel, equivalent to $\mathrm{A} 508 \mathrm{Cl} .3$ type steel. It comes from a forged nozzle and its chemical composition is given in Table 1. In this as received condition, the microstructure is a granular bainite. This microstructural state is a monitor and is not considered in the discussion of the effect of the microstructure.

\section{Table 1}

Chemical composition (wt \%)

\begin{tabular}{|c|c|c|c|c|c|c|c|c|c|}
\hline C & $\mathrm{Mn}$ & $\mathrm{Ni}$ & Mo & $\mathrm{Si}$ & $\mathrm{Cr}$ & $\mathrm{Al}$ & $S$ & $\mathrm{Cu}$ & $P$ \\
\hline 0.25 & 1.29 & 0.72 & 0.49 & 0.23 & $<0.05$ & 0.035 & 0.080 & 0.030 & 0.014 \\
\hline
\end{tabular}

In order to select the cooling rates to obtain the different microstructures, constant cooling transformation diagram (CCT) of these steel has been determined (Fig. 1). The critical cooling rate of the ferrite is between 0.3 and $1{ }^{\circ} \mathrm{C} / \mathrm{s}$ and the critical cooling rate of the bainite is between 10 and 20 ${ }^{\circ} \mathrm{C} / \mathrm{s}$. Bainite and martensite co-exist between 3 and $10{ }^{\circ} \mathrm{C} / \mathrm{s}$. Because of the austenitization at $1100^{\circ} \mathrm{C}$ during $1 / 2 \mathrm{~h}$, the prior austenite grain size is approximatively of $100 \mu \mathrm{m}$. Typical microstructures for different cooling rates are presented in figure 2 . 


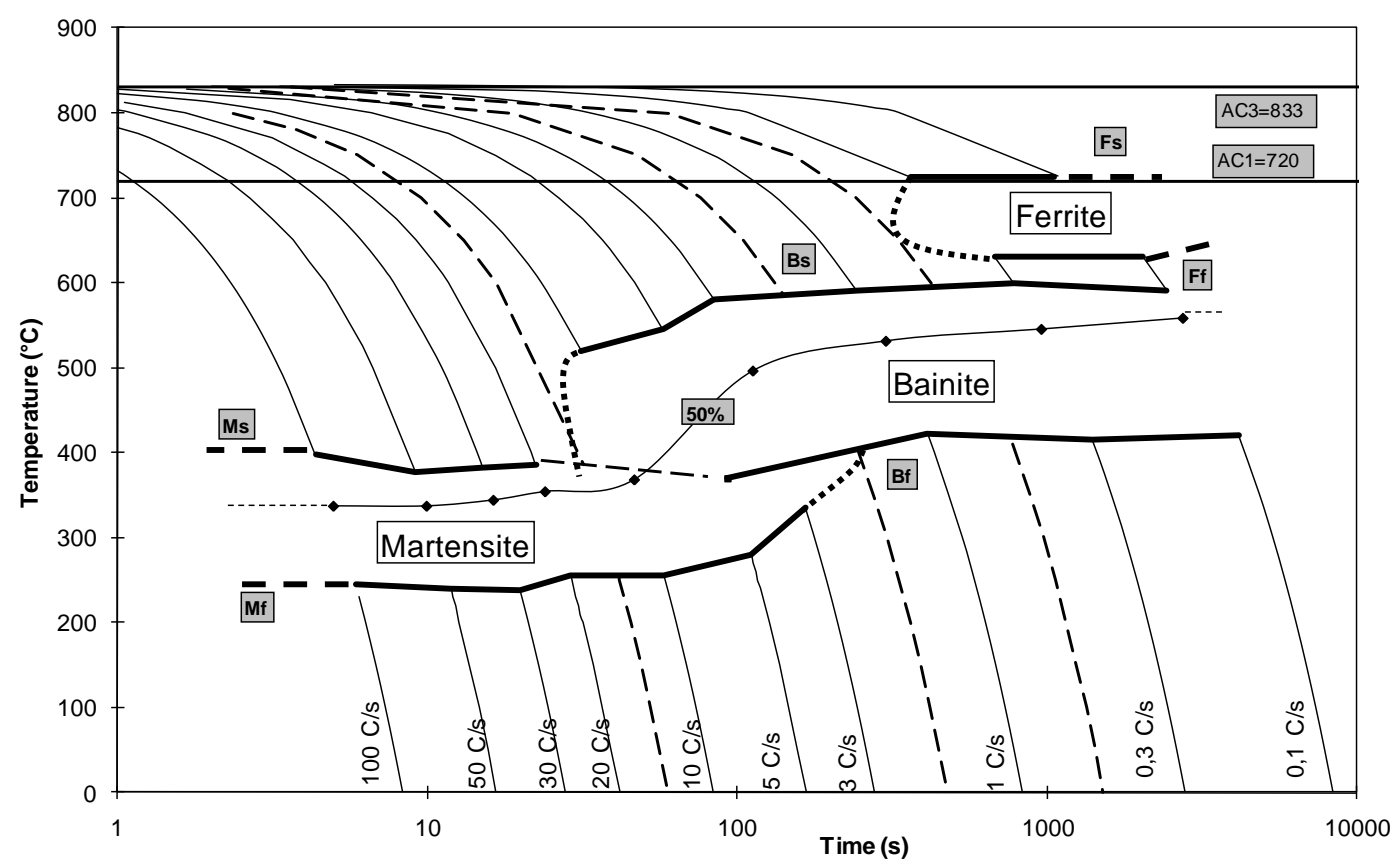

Fig. 1 Continuous cooling transformation diagram (austenitization $1100^{\circ} \mathrm{C}, 1 / 2 \mathrm{~h}$ ). The dotted lines represent the critical cooling rates of the different phases.

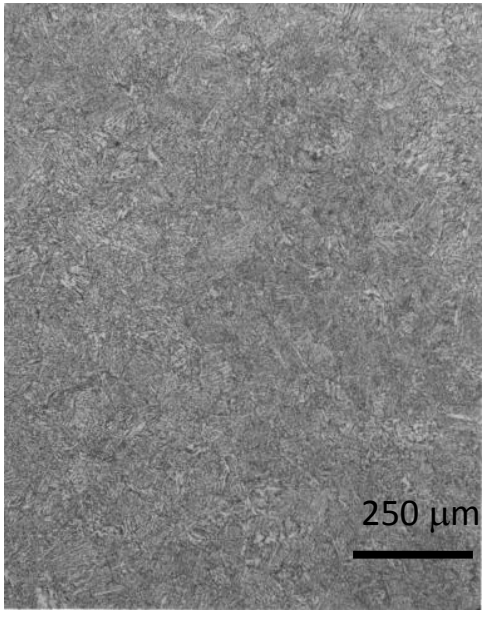

(a)

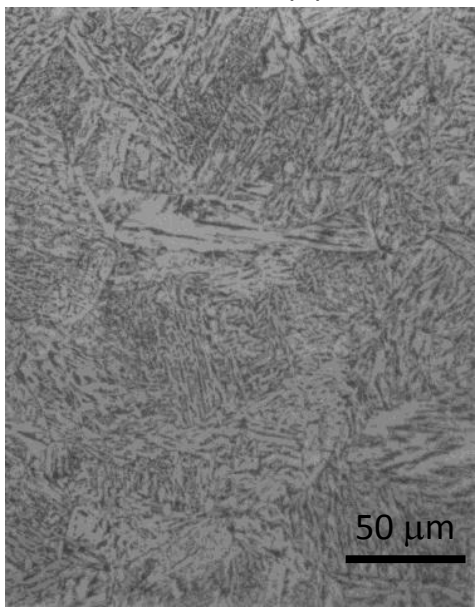

(b)

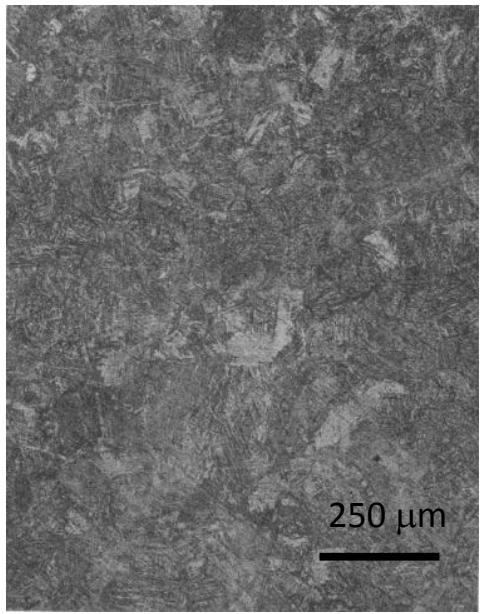

(c)

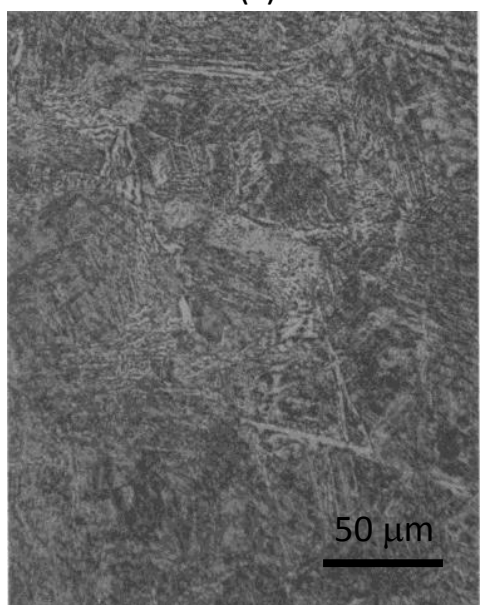

(d)

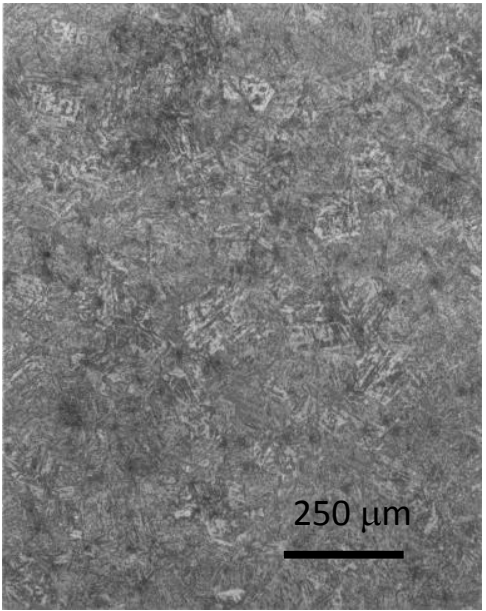

(e)

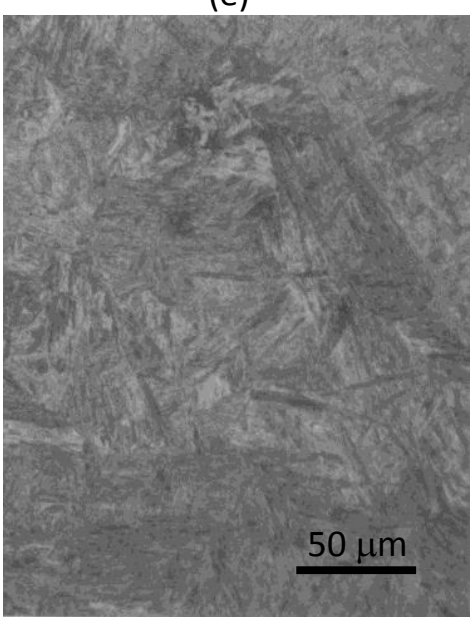

(f)

Fig. 2. Micrographs after quenching and tempering at $1(a, b), 5(c, d)$ and $30(e, f){ }^{\circ} \mathrm{C} / \mathrm{s}$ showing the effect of quenching rate on microstructure. 
Using the CCT diagram (Fig. 1), it has been decided to produce three different microstructures containing respectively $100 \%$ of bainite, $100 \%$ of martensite and a mixture of bainite and martensite. Fifteen and thirty millimetres thick plates were cut from the nozzle to prepare the different microstructures. The material was austenitized at $1100^{\circ} \mathrm{C}$ during $1 / 2 \mathrm{~h}$ then quenched at different cooling rates in order to produce martensite, bainite-martensite and bainite. The aimed cooling rates were respectively equal to $0.5,5$ and $50^{\circ} \mathrm{C} / \mathrm{s}$. During the quenches, the actual cooling rates were monitored by thermocouples at mid thickness of the plates. The average of the measured cooling rates at mid thickness between 700 and $300^{\circ} \mathrm{C}$ are, respectively for the three cooling conditions, $0.4,3$ and $37^{\circ} \mathrm{C} / \mathrm{s}$. After the quench, the plates were tempered at $610^{\circ} \mathrm{C}$ during 20 hours in order to simulate the post-weld heat treatment (PWHT). After cooling at room temperature in air, some of the martensite and bainite plates were thermally aged thanks to a step cooling heat treatment (Table 2).

Table 2. Step cooling heat treatment

\begin{tabular}{lrrrrr}
\hline Temperature $\left({ }^{\circ} \mathrm{C}\right)$ & 600 & 540 & 525 & 500 & 470 \\
\hline Time (hours) & 1 & 15 & 24 & 48 & 72 \\
\hline
\end{tabular}

Small flat tensile and sub-size Charpy specimens were machined from the heat treated plates at mid thickness. Tensile specimens have a section of $2 \times 1 \mathrm{~mm}$ and a gage length of $8 \mathrm{~mm}$. The subsize Charpy specimens have a length of $27 \mathrm{~mm}$ and a section of $3 \times 4 \mathrm{~mm}$. The notch is $1 \mathrm{~mm}$ deep. Part of the specimens were irradiated in OSIRIS reactor at $280^{\circ} \mathrm{C}$ up to a fluence of $7.75 .10^{19} \mathrm{n} / \mathrm{cm}^{2}$ $(E n>1 \mathrm{MeV})$ for tensile specimens and of $8.55 .10^{19} \mathrm{n} / \mathrm{cm}^{2}(\mathrm{En}>1 \mathrm{MeV})$ for sub-size Charpy specimens.

\section{Results}

Tensile results:

For the bainitic and martensitic microstructures, respectively noted $B$ and $M$, a large range of temperature was investigated, from the liquid nitrogen temperature up to the irradiation temperature. As commonly observed, the dependence of the yield stress with temperature is mainly affected by irradiation through the athermal stress for both microstructures. However the athermal stress increase is smaller for martensite (50 MPa) than for bainite (69 MPa).

For the other microstructures, two tests at room temperature have been performed. Before irradiation, as expected, the martensite is harder than the bainite. The bainitic-martensitic microstructure (BM) is in an intermediate situation. A simple mixing law applied to the yield stress indicates that the part of bainite is close to $65 \%$ which is in fair agreement with the estimation that can be deduced from the CCT diagram.

Ageing step cooling treatment does not change significantly the yield stress of the bainite ( $+4 \mathrm{MPa})$ but a softening is observed for the martensite $(-21 \mathrm{MPa})$. A similar evolution is observed on the ultimate tensile stress (U.T.S.). In the following, the aged bainite and the aged martensite will be referred as $\mathrm{BA}$ and MA microstructures.

The comparison of the yield stresses before and after irradiation is presented in table 3: it appears that the higher is the initial yield stress, the smaller is the increase of yield stress. The as-received material (AR) has the lowest initial yield stress and ultimate tensile stress (U.T.S.) but shows the largest hardening after irradiation.

The relation between the increase of yield and ultimate tensile stresses and the respective initial value are presented in figure 3 . The increase of yield stress is linearly decreasing as a function of the yield stress before irradiation. For all the coarse grained microstructures, the increase of ultimate tensile stress appears to be of the same order. 
The uniform elongation is not significantly modified by irradiation but the elongation at fracture shows a slight decrease at room temperature for all microstructures.

\section{Table 3}

Values and irradiation induced increases of $0.2 \%$ yield stresses and ultimate tensile stresse at room temperature (strain rate: $5.10^{-4} \mathrm{~s}^{-1}$ ).

\begin{tabular}{c|cccc|ccccc}
\hline & \multicolumn{4}{|c|}{ 0.2\% Y.S. at R.T. (MPa) } & \multicolumn{4}{c}{ U.T.S. at R.T. (MPa) } \\
\hline Material & $\begin{array}{c}\text { Un- } \\
\text { irradiated }\end{array}$ & irradiated increase & $\%$ & $\begin{array}{c}\text { Un- } \\
\text { irradiated }\end{array}$ & irradiated & increase & $\%$ \\
\hline AR & 449 & 561 & 112 & +25 & 595 & 698 & 103 & +17 \\
\hline B & 494 & 595 & 101 & +21 & 638 & 717 & 79 & +12 \\
\hline BA & 498 & 598 & 100 & +20 & 649 & 737 & 88 & +13 \\
\hline BM & 545 & 644 & 99 & +18 & 698 & 786 & 88 & +13 \\
\hline MA & 619 & 714 & 95 & +15 & 735 & 820 & 85 & +12 \\
\hline M & 640 & 730 & 91 & +14 & 751 & 838 & 88 & +12 \\
\hline
\end{tabular}

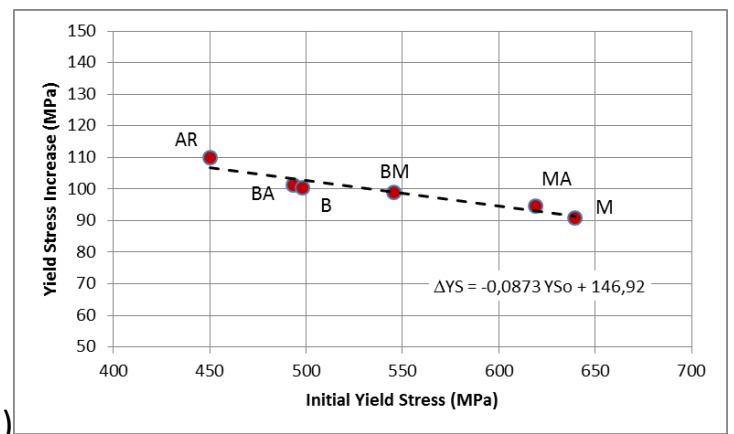

a)

Fig. 3. Irradiation induced increase in $0.2 \%$ yield (a)

b)

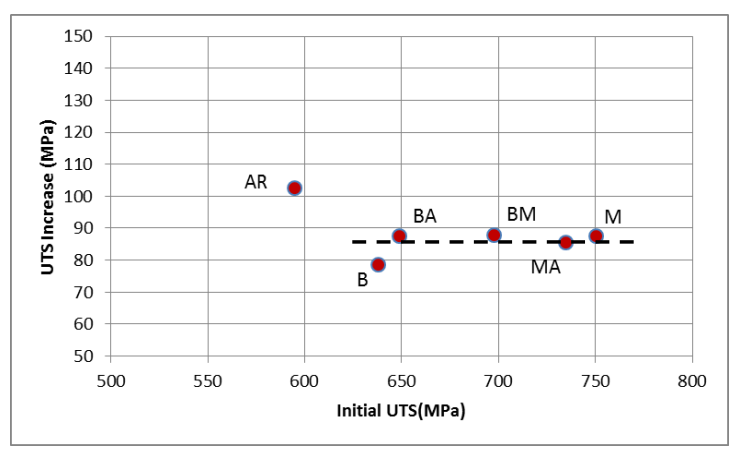
a function of the values before irradiation.

\section{Subsize Charpy results}

Subsize Charpy specimens were tested on $50 \mathrm{~J}$ pendulums in the temperature range $\left[-160^{\circ} \mathrm{C},+\right.$ $\left.160^{\circ} \mathrm{C}\right]$. The variations of the fracture energies with test temperature have been fitted using a hyperbolic tangent function (Fig. 4). The transition temperatures are derived from the fits for a fracture energy of $3.5 \mathrm{~J}$. The transition temperatures and the upper shelf energies are presented in table 4.

As expected, martensite is more resilient than bainite and much more sensitive to the ageing heat treatment: the step cooling heat treatment induces a shift of $51^{\circ} \mathrm{C}$ for martensite and only $15^{\circ} \mathrm{C}$ for bainite.

The average value of irradiation shift for all the microstructures is $60^{\circ} \mathrm{C}$ and the experimental scatter is about $\pm 15^{\circ} \mathrm{C}$. Despite the use of sub-sized Charpy specimens, this average value is in fair agreement with the prevision of the RSEM embrittlement formula $\left(\approx 70^{\circ} \mathrm{C} \pm 20^{\circ} \mathrm{C}\right)$ [17]. It is of interest to note that there is no direct effect of the initial transition temperature on the irradiation induced shift (Fig. 5).

After irradiation, the as-received and bainitic materials have the smallest shifts. The bainiticmartensitic microstructure has the largest transition temperature shift and a significant decrease on the upper shelf. Small decreases of upper shelf are measured for the bainite and martensite and a larger one for the aged martensite.

Due to the experimental uncertainties, it is difficult to distinguish a clear microstructure effect on the irradiation shifts: bainite and martesnsite have a similar shift. However, the difference of $25^{\circ} \mathrm{C}$ between the shifts of the bainitic and banitic-martensitic microstructures could be considered as significant. 


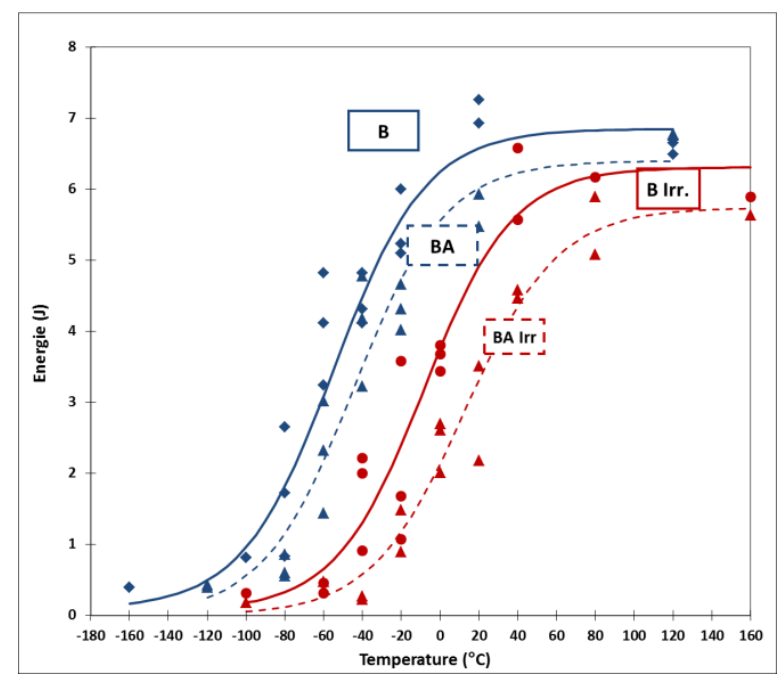

(a)

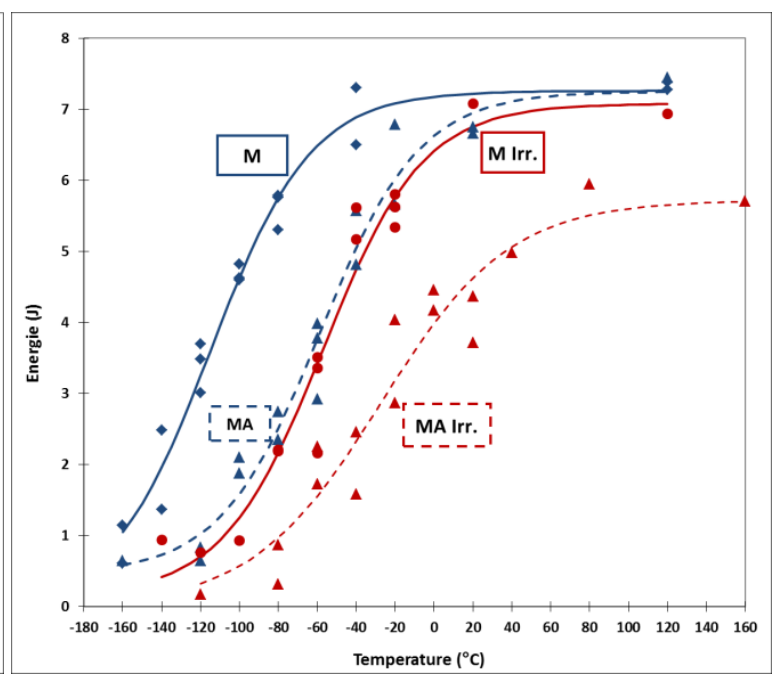

(b)

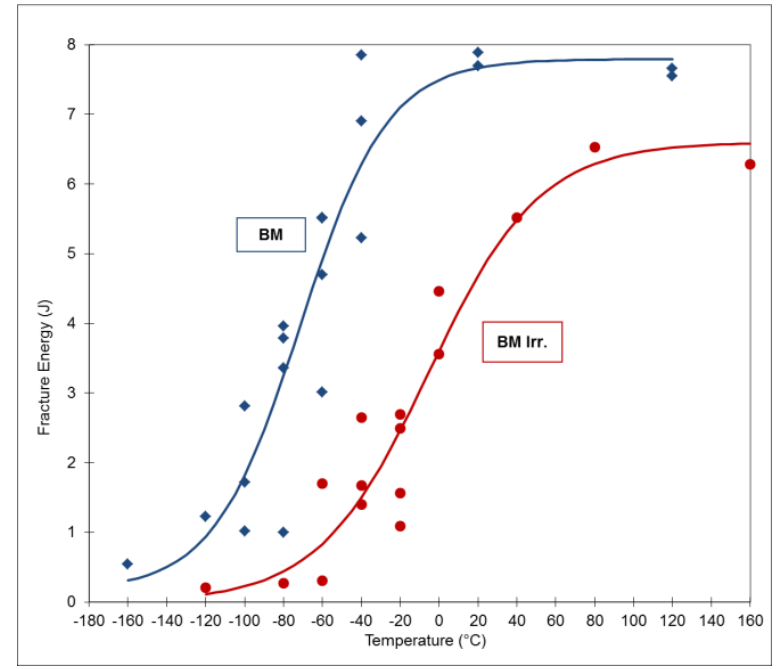

(c)

Fig. 4: Fracture Energy vs test temperature for the bainitic (a), martensitic (b) and bainitic-martensitic (c) microstructures. Blue and red symbols correspond respectively to the un-irradiated and irradiated conditions. Triangles and dotted lines are for step cooled materials.

\section{Table 4}

Values and irradiation induced variations of the transition temperatures and of the upper shelf energies

\begin{tabular}{|c|c|c|c|c|c|c|}
\hline \multirow[b]{2}{*}{ Material } & \multicolumn{3}{|c|}{ Transition Temperature $\left({ }^{\circ} \mathrm{C}\right)$} & \multicolumn{3}{|c|}{ Upper Shelf Energy $(\mathrm{J})$} \\
\hline & $\begin{array}{c}\text { Un- } \\
\text { irradiated }\end{array}$ & Irradiated & Shift & $\begin{array}{c}\text { Un- } \\
\text { irradiated }\end{array}$ & Irradiated & Drop \\
\hline AR & -30 & +18 & 48 & 7.5 & 7.0 & -0.5 \\
\hline B & -54 & -4 & 50 & 6.9 & 6.3 & -0.6 \\
\hline BA & -40 & 23 & 63 & 6.4 & 5.7 & -0.7 \\
\hline BM & -77 & -2 & 75 & 7.8 & 6.6 & -1.2 \\
\hline MA & -65 & -12 & 53 & 7.4 & 5.7 & -1.7 \\
\hline M & -116 & -59 & 57 & 7.3 & 7.1 & -0.2 \\
\hline
\end{tabular}




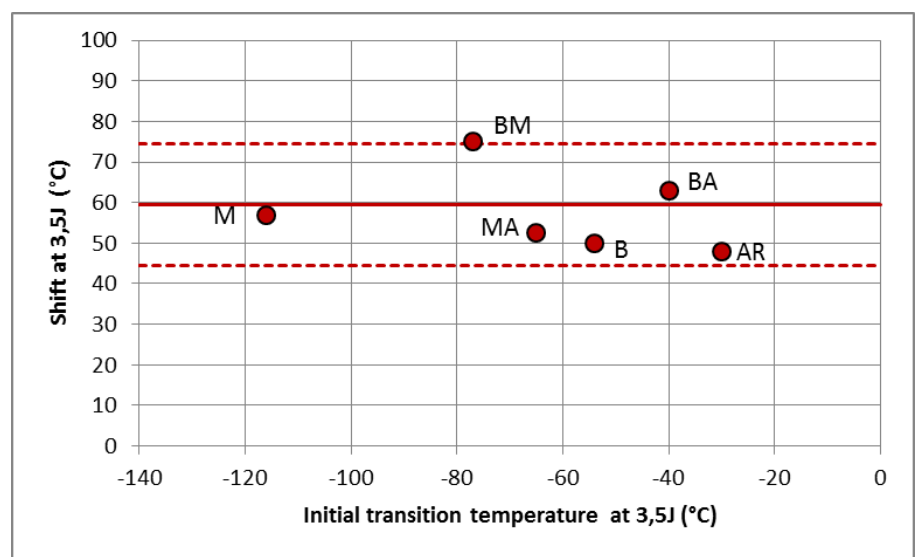

Fig. 5: Irradiation induced shift vs the transition temperature before temperature for all the tested microstructures. The continuous line represent the average values of the shift $\left(60^{\circ} \mathrm{C}\right)$ The experimental scatter band represented by the dotted lines is $\pm 15+{ }^{\circ} \mathrm{C}$.

\section{Discussion}

For the coarse grained microstructures, the embrittlement under irradiation represented by the shift at 3.5 $\mathrm{J}$ is plotted against the hardening induced by irradiation represented by the increase in yield stress (Fig.6a). The average slope for all the data presented above is close to 0.6 and the scatter is about $15^{\circ} \mathrm{C}$.

PWR vessel steels sensitivity to non-hardening embrittlement (NHE) can be evaluated through this slope i.e. the embrittlement on hardening ratio (EHR). High values of this ratio could be considered as the signature of a NHE mechanism triggered by irradiation. The values of this ratio for the present results are given in table 4 . Despite the fact that these values have been obtained using sub-size specimens, they are comparable to usual values found for forged RPV steels using usual specimens [18-22]. This is due to the fact that the transition temperature determined by full size Charpy specimens mainly differs by an offset from the transition temperature determined with subsize specimens [23].

There are, of course, a lot of experimental uncertainties included in the determination of the EHR. However, according to the present values, the bainite seems to be less sensitive to irradiation embrittlement than the martensite and the bainite-martensite appears to be the most sensitive microstructure.

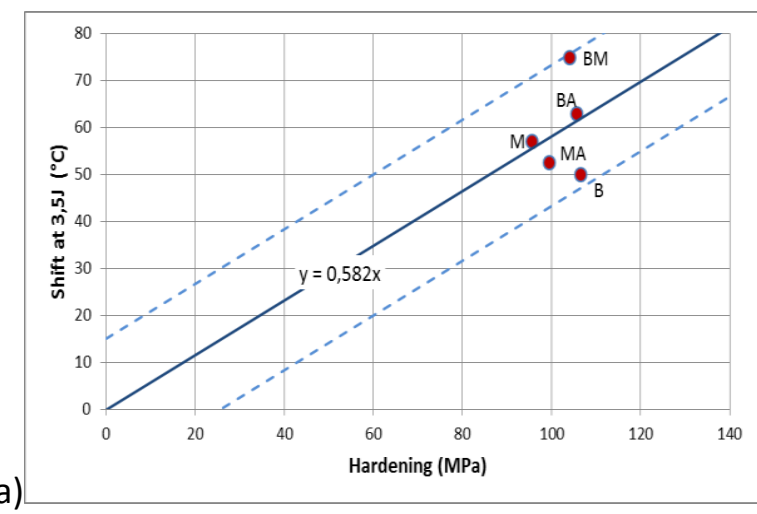

b)

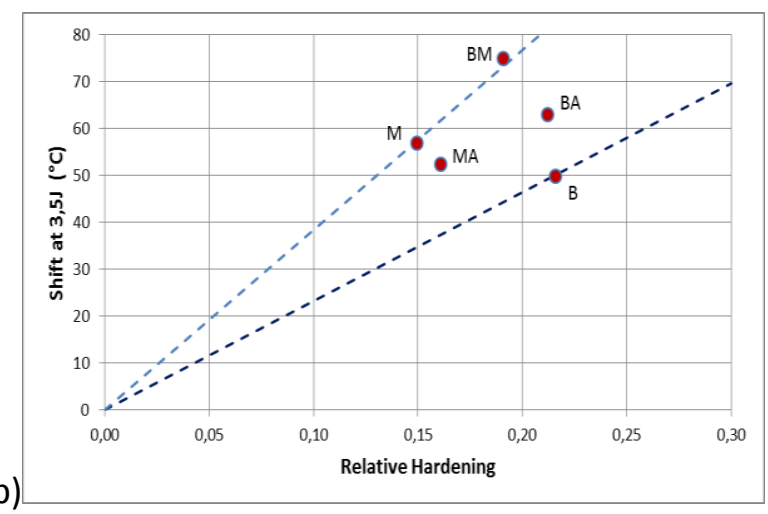

Fig. 6: Transition temperature shifts versus absolute (a) or relative (b) increase of the yield stress after irradiation. 
Table 4 : Irradiation shift, hardening and embrittlement-hardening ratios (EHR).

\begin{tabular}{cccccc}
\hline Material & Shift $\left({ }^{\circ} \mathrm{C}\right)$ & $\begin{array}{c}\text { Hardening* } \\
(\mathrm{MPa})\end{array}$ & $\begin{array}{c}\text { EHR } \\
\left({ }^{\circ} \mathrm{C} / \mathrm{MPa}\right)\end{array}$ & $\begin{array}{c}\text { Relative } \\
\text { Hardening* }(\%)\end{array}$ & $\begin{array}{c}\text { EHR' } \\
\left({ }^{\circ} \mathrm{C} / \%\right)\end{array}$ \\
\hline B & 50 & 106 & 0.47 & 22 & 2.32 \\
\hline BA & 63 & 106 & 0.60 & 21 & 2.97 \\
\hline BM & 75 & 104 & 0.72 & 19 & 3.93 \\
\hline MA & 53 & 99 & 0.53 & 16 & 3.27 \\
\hline M & 57 & 95 & 0.60 & 15 & 3.82 \\
\hline
\end{tabular}

*The hardening is corrected, here, to take into account the difference in fluence between tensile and Charpy specimens by multiplying the measured hardening by the squared root of the ratio of the fluences.

A clearer view of the sensitivity of the different materials to NHE embrittlement can be obtained by plotting the shift as a function of the relative hardening which is the ratio of the increase of yield stress after irradiation and the yield stress before irradiation (Fig.6b). On this plot, martensitic bearing microstructures appears to be more sensitive than the bainite material for a same relative hardening. Aged materials have an intermediate behaviour. The bainitic-martensitic material seems to inherit the NHE sensitivity of the martensite and the irradiation induced hardening of the bainite. These is quantified in table 4 through the EHR' value which is the ratio of the shift and the relative hardening in \%. According to this index, the classification of the microstructures by decreasing sensitivity to NHE is: $\mathrm{BM}>\mathrm{M}>\mathrm{MA}>\mathrm{BA}>\mathrm{B}$

To understand the difference of NHE sensitivity of the different microstructures, SEM examinations of the fracture surface of the subsize charpy specimens were performed for the microstructures without prior thermal ageing; i.e. B, BM and M (Figs. 7 and 8). Ductile fracture can be observed at the notch root when fracture energy is large enough (> $1 \mathrm{~J}$ ) for the three microstructures. But differences are observed for the brittle fracture surfaces with or without prior ductile propagation:

- $\quad$ For the un-irradiated specimens:

- bainitic microstructure: the brittle fracture is transgranular cleavage (Fig 7.a).

- martensitic and bainitic-martensitic microstructures: the brittle fracture is transgranular cleavage with few intergranular facets(Fig. 7.b and c).

- For the irradiated specimens:

- bainitic microstructure: the brittle fracture is transgranular cleavage (Fig. 8.a).

- martensitic microstructure: the brittle fracture is mixed transgranular/intergranular but mostly intergranular (Fig. 8.b).

0 bainitic-martensitic microstructure: mixed transgranular/intergranular fracture is observed but mostly transgranular (Fig. 8.c)
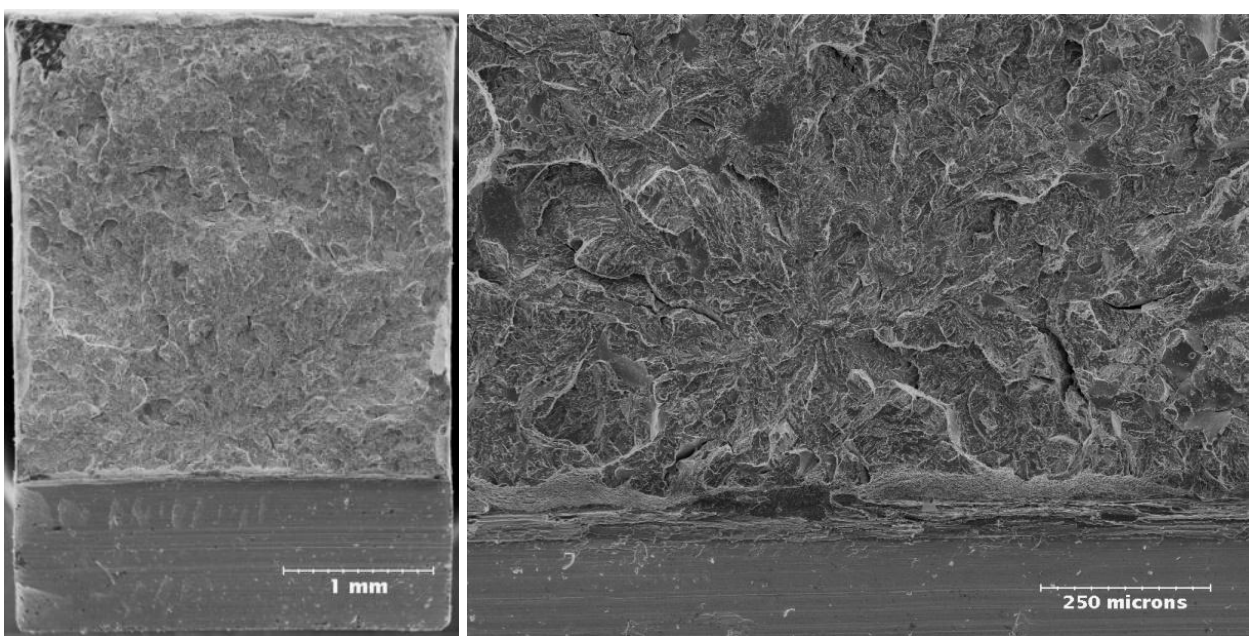

Un irradiated bainite specimen broken at $-80^{\circ} \mathrm{C}-$ fracture energy $1.93 \mathrm{~J}$ 


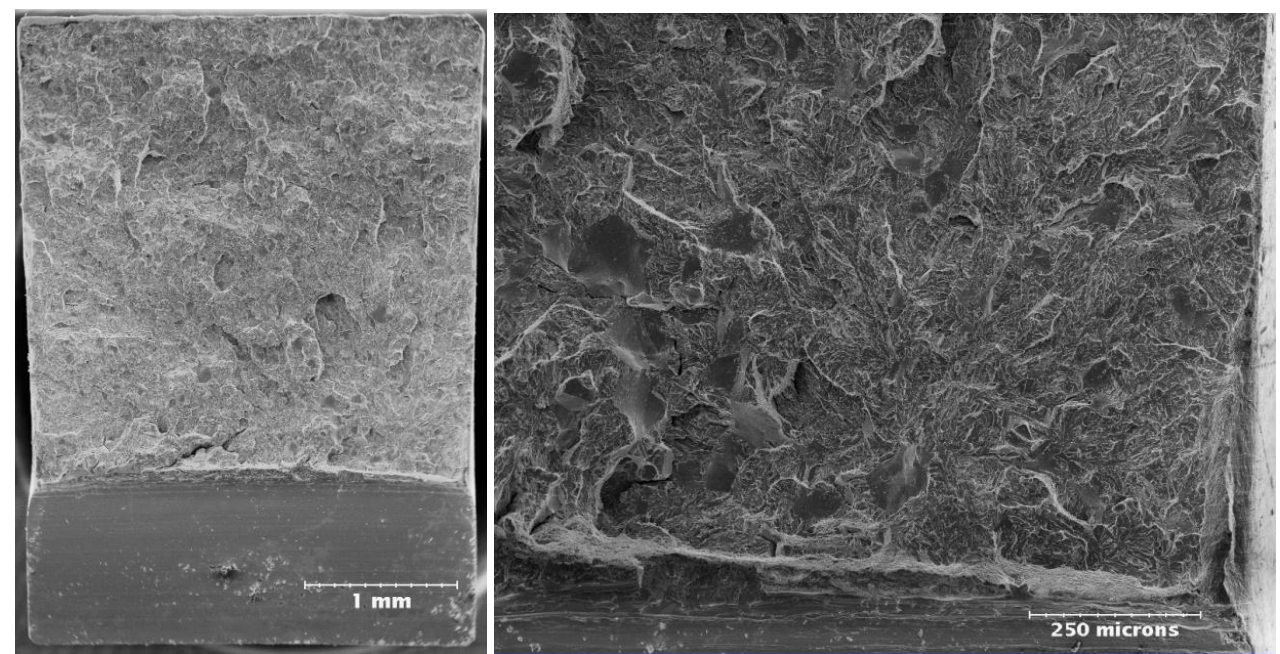

Un-irradiated martensite specimen broken at $-160^{\circ} \mathrm{C}-$ fracture energy $1.86 \mathrm{~J}$

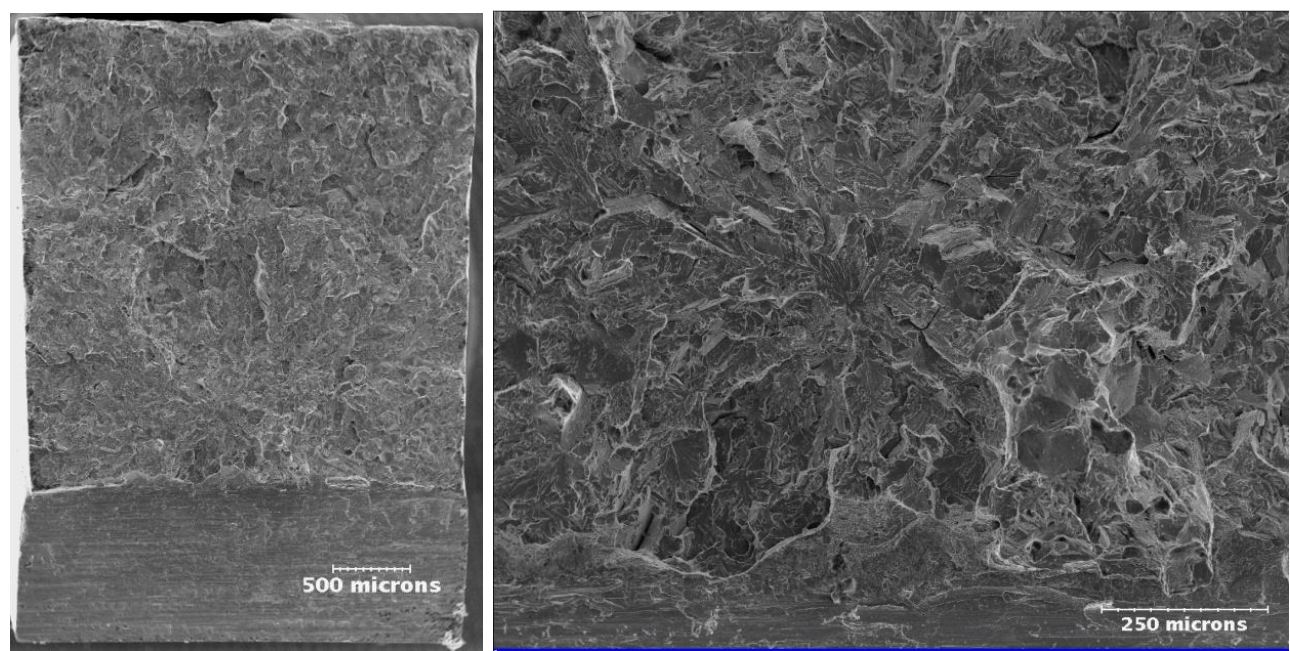

Un irradiated bainite-martensite

Fig. 7. SEM micrographs of un-irradiated Charpy specimens. A general view of the fracture is on the left side and detailed view of the fracture close to the notch root is on the right side.
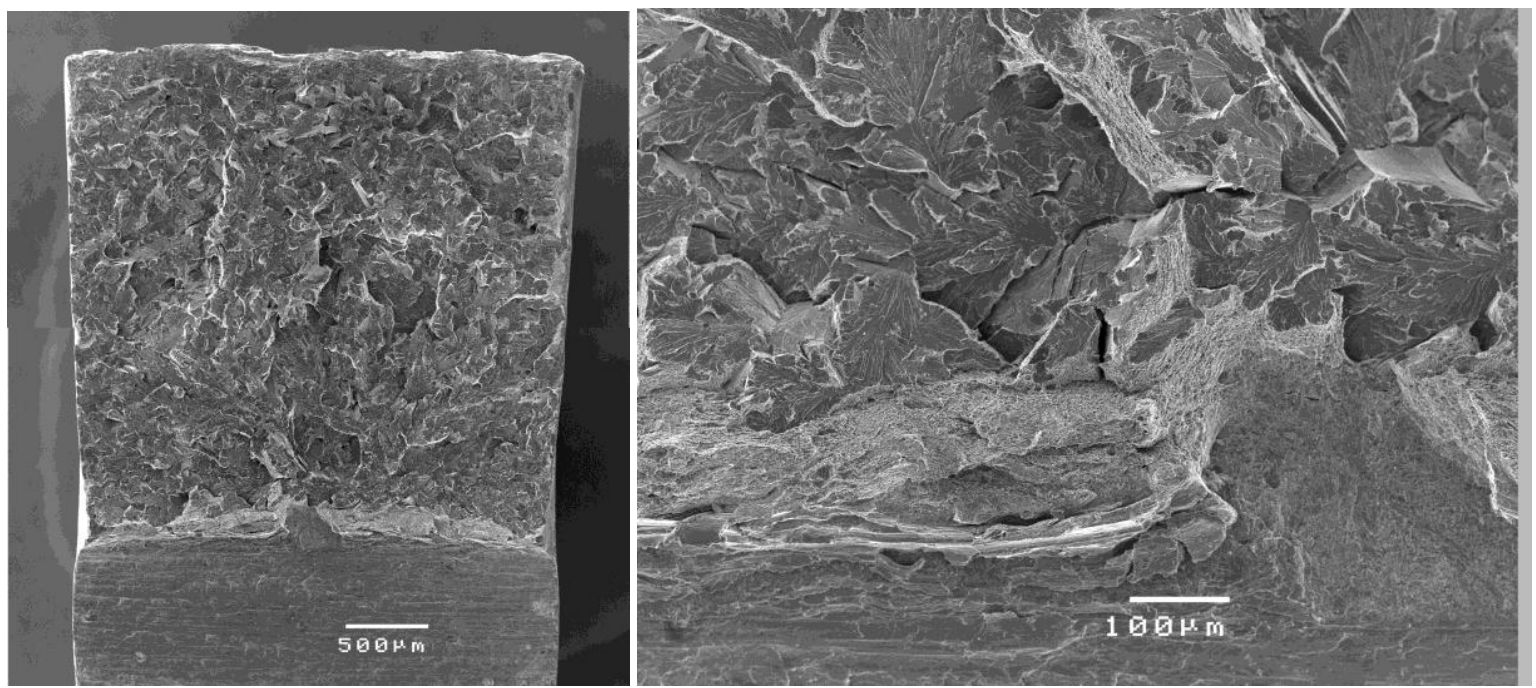

Irradiated Bainite: specimen broken at $-20^{\circ} \mathrm{C}-$ fracture energy $1.68 \mathrm{~J}$ 

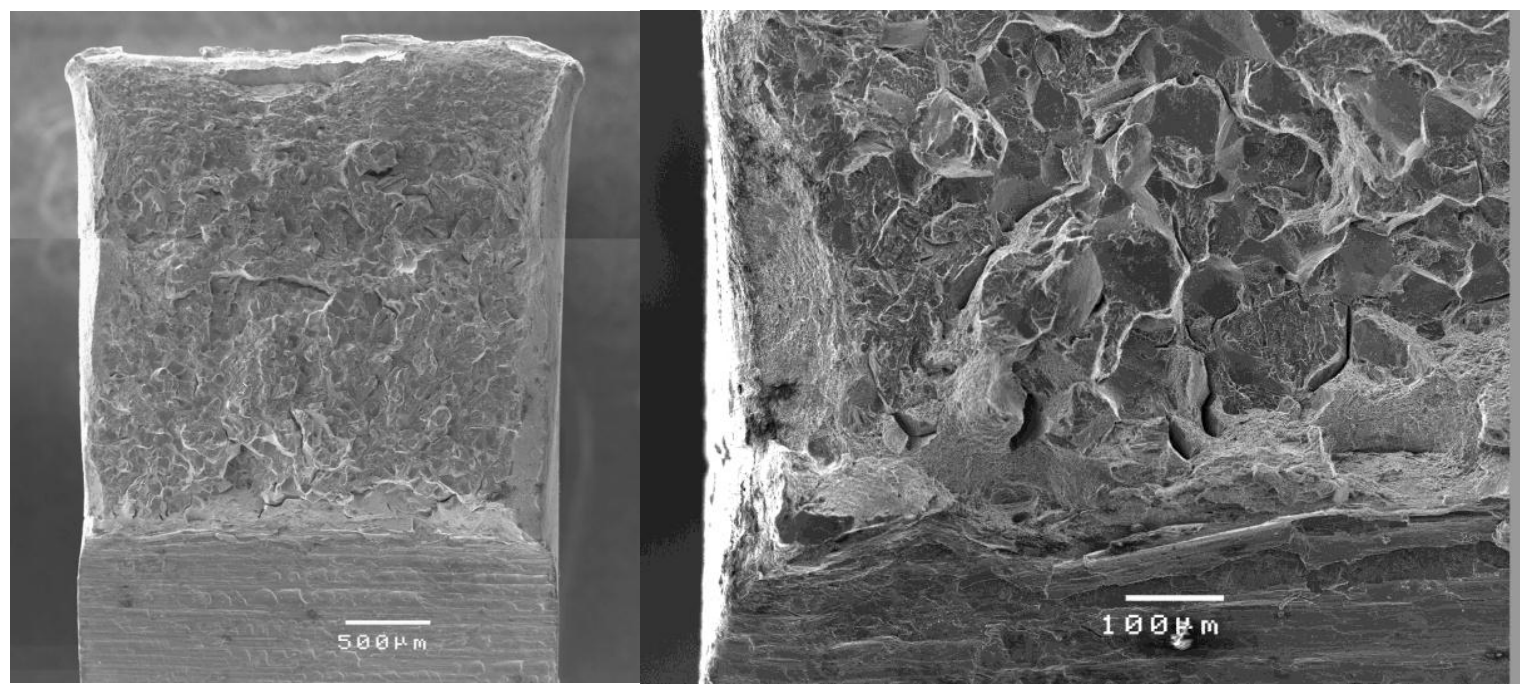

Irradiated Martensite: specimen broken at $-60^{\circ} \mathrm{C}-$ fracture energy $2.16 \mathrm{~J}$
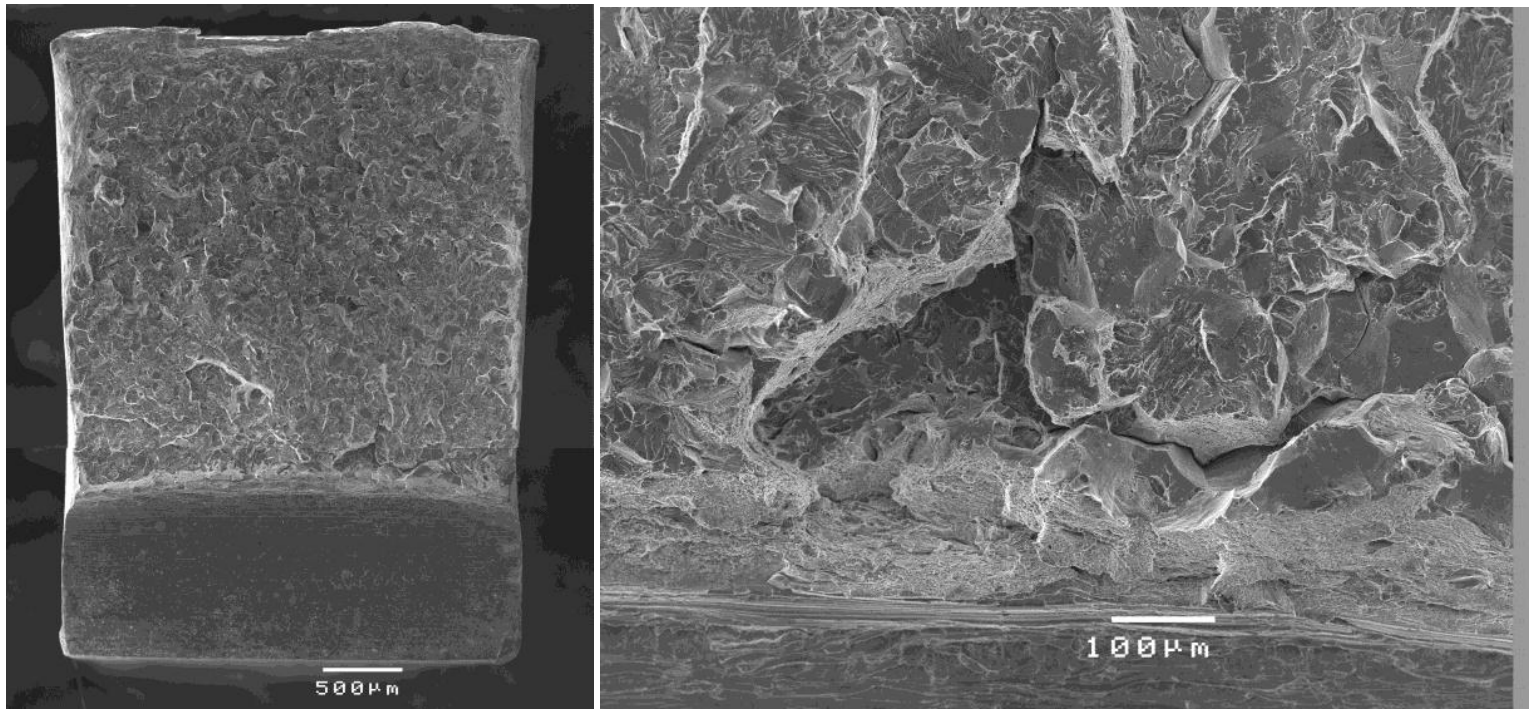

Irradiated Bainite-Martensite: Specimen broken at $-20^{\circ} \mathrm{C}$ - fracture energy $1.56 \mathrm{~J}$

Fig. 8. SEM micrographs of irradiated subsize Charpy specimens. A general view of the fracture is on the left side and detailed view of the fracture close to the notch root is on the right side.

From these observations, it could be assumed that the difference in sensitivity to irradiation NHE between bainitic and martensitic microstructures is related to the increase of intergranular fracture for the martensite under irradiation. For the bainitic-martensitic microstructure, the importance of the sensitivity would be understood, schematically, as the synergetic effect of the increase of intergranular fracture in the martensitic part of the material and of the relatively larger irradiation hardening of the bainite part.

The microstructures of this study share some similarity with the cases shortly presented in the introduction: a moderately high level of $P$ and a coarse grained microstructure. But only the martensitic microstructures exhibits a trend to the increase of brittle intergranular fracture after irradiation as the brittle fracture of the bainite remains transgranular cleavage. This result shows the importance of the metallurgical microstructure on sensitivity to irradiation enhanced BIF. The microstructure appears to play a similar role as in the cases of thermal ageing presented in the introduction [5-7]. 
The physical origin of the enhancement of BIF by neutron irradiation remains an open question. However the crystallographic origin is probably the most convincing: the difference in misorientation of interfaces between bainite and martensite modifies the segregation of impurities and consequently the possibility of BIF. This explanation has been already proposed to rationalize the difference of susceptibility to temper embrittlement of different microstructures [8-10, 24]. The difference of interfaces misorientation of the present martensitic and bainitic microstructures is shown through the $\Sigma 3$ type boundaries identified by EBSD (Fig. 9). This special boundary has a low energy and is weak trap for solute elements. The large amount of $\Sigma 3$ type boundaries of the martensite will prevent the radiation induced segregation of impurities like phosphorus inside the prior austenitic grain and, consequently, favour the segregation on the prior austenite grain boundaries.

Other origins of the sensitivity of martensitic microstructures compare to bainite can be invoked like the difference in carbides populations and also potential micro-mechanical effects induced by the difference in crystallography. Of course, several causes can coexist and further metallurgical and micromechanical studies are needed to understand and evaluate them separately.

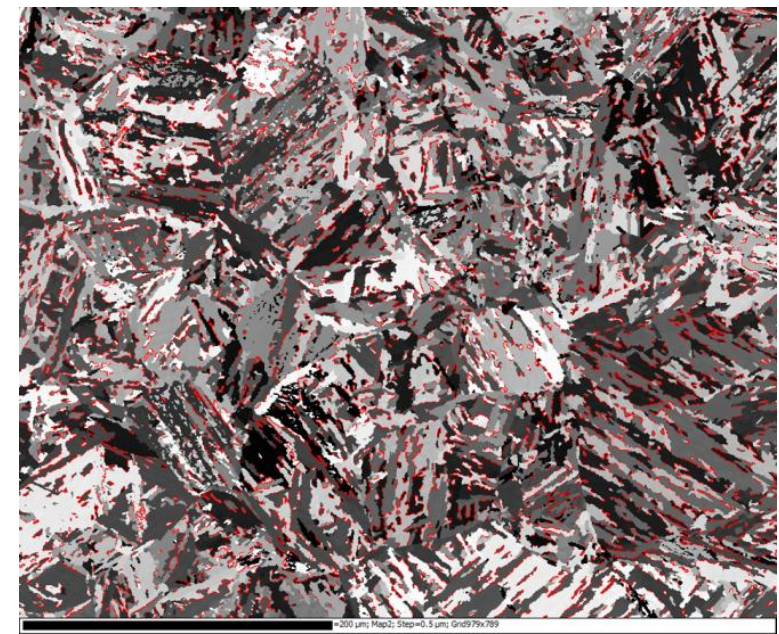

(a)

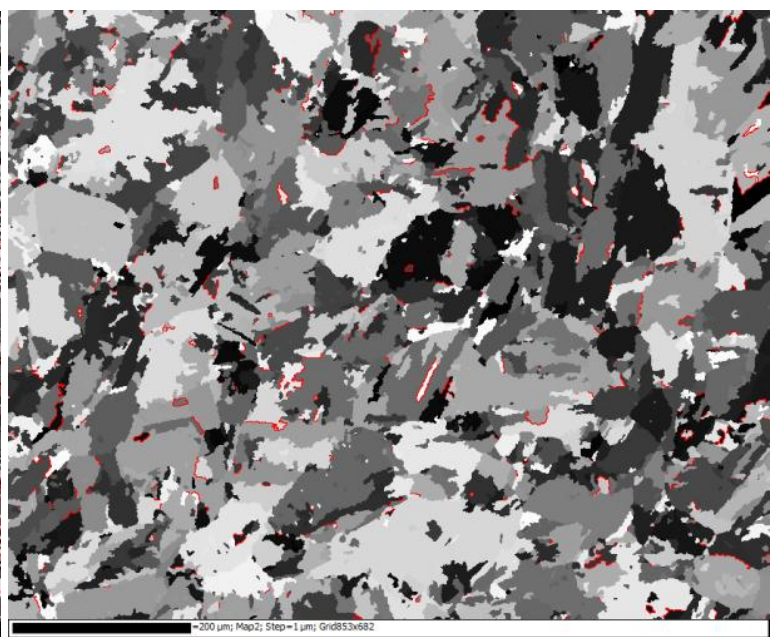

(b)

Fig. 9: EBSD maps (Euler angle $\phi_{1}$ ) showing in red the $\Sigma 3$ boundaries. (a) martensitic (M) microstructure (b) bainitic (B) microstructure. The black line below the images represents $200 \mu \mathrm{m}$.

\section{Conclusions}

Irradiation induced hardening and embrittlement have been compared for three different coarse grained microstructures (bainite, bainite-martensite and martensite) produced from the same RPV steel. The mains conclusions are:

(1) Before irradiation, martensite has the highest initial yield stress and the lowest initial transition temperature. Bainite has the lowest initial yield stress and the highest initial transition temperature. The bainitic-martensitic microstructure has an intermediate behaviour.

(2) A step cooling heat-treatment has been applied to the bainitic and martensitic microstructures. Martensite appears to be more sensitive to thermal ageing than the bainite. 
(3) There is no direct effect of the initial transition temperature on the shift. Bainite and martensite have a comparable irradiation induced temperature transition shifts but irradiation hardening is smaller for martensite than for bainite.

(4) The thermal ageing of the martensite and the bainite before irradiation does not reduce the irradiation induced embrittlement.

(5) Bainite appears to be less sensitive to non-hardening embrittlement than martensite. The onset of brittle intergranular fracture after irradiation for the martensitic microstructure is the probable origin of this difference of sensitivity to NHE. A significant difference in low energy boundaries between the two microstructures could explain this behaviour.

(6) For the level of neutron fluence of this study, the developments of intergranular fracture and consequently of the NHE do not produce a significant additional shift for martensite compared to bainite.

(7) However, the bainitic-martensitic microstructure has the largest irradiation induced shift and is the most sensitive to non-hardening embrittlement amongst all the tested microstructures. The enhancement of the sensitivity would be due to a synergetic effect of the intergranular fracture in the martensitic part of the material and of the irradiation hardening of the bainite part.

These results show that the microstructure is an important parameter to control the irradiation enhancement of the brittle intergranular fracture in RPV steels. Further metallurgical and micromechanical studies are needed to fully understand the origin of the enhancement of the brittle intergranular fracture for the martensite after irradiation. The enhanced sensitivity to nonhardening embrittlement of the bainitic-martensitic microstructure is also an important practical issue to check.

\section{Aknowledgements}

The authors wish to thank T. Guilbert for the CCT diagram determination, A. Bougault for the SEM micrographs of the un-irradiated materials and J.J. Espinas for the SEM micrographs of the irradiated materials.

\section{References}

[1] P. G. Bocquet, J.C. Saint-Ignan, R.P. Blondeau, Application of new types of ingots to the manufacturing of heavy pressure vessel forgings, Steel Forgings, ASTM STP 903, 1986, 367-384 [2] J-T Kim, H-K. Kwon, K-C Kim, J-M Kim, Improved mechanical properties of the A508 Cl3 steel for nuclear pressure vessel through steel making, Steel Forgings, Second Volume, ASTM STP 1259 (1997) $18-32$

[3] H.-W. Viehrig , J. Boehmert, J. Dzugan, Some issues by using the master curve concept, Nuclear Engineering and Design 212 (2002) 115-124

[4] P. Bocquet, D. Buisine, L. Dunand-Roux, Les facteurs métallurgiques de la ténacité de l'acier de cuve, Endommagement des matériaux dans les centrales nucléaires, Eyrolles editor (1997) 121-152 [5] S. G. Druce, G. Gage and G. Jordan, Effect of ageing on properties of pressure vessel steels, Acta metall. Vol. 34. No. 4. (1986) 641-652 
[6] I. A. Vatter, C. A. Hippsley and S. G. Druce, Review of Thermal Ageing Data and its Application to Operating Reactor Pressure Vessels, Int. 1. Pres. Ves. \& Piping S4 (1993) 31-48

[7]P. Joly, F. Roch, C. Primault, effect of thermal ageing on properties of pressure vessel low alloy steel, Proc. of ASME 2013 PVP Conference, Paper PVP2013-97643

[8] S. Raoul, B. Marini, A. Pineau, Effect of microstructure on the susceptibility of a A-533 steel to temper embrittlement, Journal of Nuclear Materials 257 (1998) 199-205

[9] M.J. Balart, J.F. Knott, Low temperature fracture properties of DIN 22NiMoCr37steel in finegrained bainite and coarse-grained tempered embrittled martensite microstructures, Engineering Fracture Mechanics 75 (2008) 2480-2513

[10] S.G. Park ,K.H. Lee, M.C. Kim, B.S. Lee, "Effects of boundary characteristics on resistance to temper embrittlement and segregation behavior of $\mathrm{Ni}-\mathrm{Cr}-\mathrm{Mo}$ low alloy steel", Materials Science \& Engineering A 561 (2013) 277-284

[11] R. J McElroy, C.A. English, A.J. Foreman, G. Gage, J.M. Hyde, P.H.N. Ray, I.A. Vatter, Temper embrittlement, irradiation induced phosphorus segregation and implications for post-irradiation annealing of reactor pressure vessels, ASTM STP 1325 (1999) 296-316

[12] Z. Lu, R.G. Faulkner, R.B. Jones, P.E.J. Flewit, Radiation and thermally-induced phosphorus intergranular segregation il pressure vessel steels, ASTM STP 1475 (2005) 180-194

[13] Y. Nishiyama, M. Yamaguchi, K. Onizawa, A. Iwase, H. Matsuzawa, Irradiation-induced grainboundary solute segregation and its effect on ductile-to-brittle transition temperature in RPV steels, ASTM STP 1513 (2010) 153-163

[14] B.A. Gurovich, E.A. Kuleshova, Ya.I. Shtrombakh, O.O. Zabusov, E.A. Krasikov, Intergranular and intragranular phosphorus segregation in Russian pressure vessel steels due to neutron irradiation, Journal of Nuclear Materials 279 (2000) 259-272

[15] R.K. Nanstadt, D.E. McCabe, M.A. Sokolov, C.A. English, S.R. Ortner, Investigation on temper embrittlement in RPV steels following thermal ageing, irradiation and thermal annealing, ASTP STP 1405 (2001) 356-382

[16] Y. Nishiyama, K. Onizawa, M. Suzuki, J.W. Anderegg, Y. Nagai, T. Toyama, M. Hasegawa, J. Kameda, Effects of neutron-irradiation-induced intergranular phosphorus segregation and hardening on embrittlement in reactor pressure vessel steels, Acta Materialia 56 (2008) 4510-4521

[17] RSEM 2010 - Paragraph B6311

[18] J. Böhmert, H.-W. Viehrig, A. Ulbricht, Correlation between irradiation-induced changes of microstructural parameters and mechanical properties of RPV steels, Journal of Nuclear Materials 334 (2004) 71-78

[19] R. Chaouadi, R. Gérard, A-S Bogaerts, Assessment of the French and US embrittlement trend curves applied to RPV materials irradiated in the BR2 materials test reactor, Proc. Of Fontevraud 7 Conference, 26-30 September 2010, Avignon, France

[20] B. Tanguy, C. Bouchet, S. Bugat, J. Besson, Local approach to fracture based predictionof the DT56J and DT KIc100 shifts due to irradiation for an A508 pressure vessel steel, Engineering Fracture Mechanics 73 (2006) 191-206

[21] G.R. Odette, P.M. Lombrozzo, R.A. Wullaert, Relationship between irradiation hardening and embrittlement of pressure vessel steels, ASTM STP 870 (1985) 840-860

[22] M.A. Sokolov, R. K. Nanstad, Comparison of irradiation-Induced shifts of KJ cans Charpy Impact Toughness for reactor pressure vessel steels, ASTM STP 1325 (1999) 167-190

[23] Y.I. Shtrombakh, Examination of VVER-440 RPV steel re-irradiation behavior using materials from operating units, International Journal of Pressure Vessels and Piping 77 (2000) 585-590

[24] R. Viswanathan and A. Joshi, Effect of Microstructure on the Temper Embrittlement of Cr-Mo-V Steels, Metallurgical Transactions A Vol. 6A (1975) 2289-2297 